\title{
Glycoside Bond Formation via Acid-Base Catalysis
}

2011

Vol. 13, No. 14

3612-3615

\author{
Amit Kumar, Vipin Kumar, Ravindra T. Dere, and Richard R. Schmidt* \\ Fachbereich Chemie, Universität Konstanz, Fach 725, D-78457 Konstanz, Germany \\ richard.schmidt@uni-konstanz.de
}

Received May 9, 2011

\section{ABSTRACT}

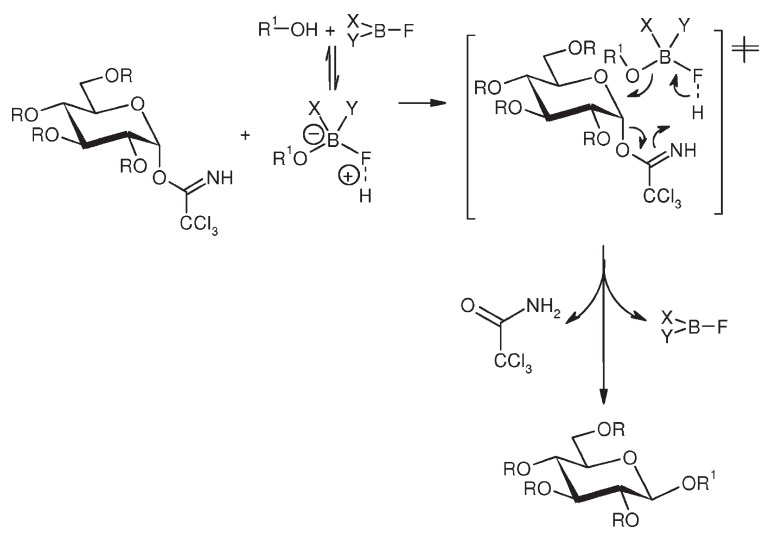

Acid-base catalyzed glycosyl donor and then glycosyl acceptor activation with phenylboron difluoride or diphenylboron fluoride permits hydrogen bond mediated intramolecular $\mathrm{S}_{\mathrm{N}} 2$-type glycosidation in generally high anomeric selectivity.

Major problems associated with glycoside bond formation have been addressed by the many recent advances in glycoside synthesis. Efficient strategies and powerful methods for accessing complex oligosaccharides and glycoconjugates of biological significance have been developed. ${ }^{1-5}$ However, the synthesis of glycosidic linkages is still by no means routine and not comparable to peptide and nucleotide synthesis. Often careful optimization of all parameters including the leaving group, promoter/catalyst, protecting group, and glycosidation conditions is crucial for high yield and high stereoselectivity. Hence, new conceptual approaches to glycosidation are still welcome to meet the intrinsic diversity of carbohydrates.

To overcome some difficulties of intermolecular glycosidations, particularly the demanding anomeric stereocontrol,

(1) (a) Schmidt, R. R. Angew. Chem. 1986, 98, 213-236. Angew. Chem., Int. Ed. Engl. 1986, 25, 212-235. (b) Zhu, X.; Schmidt, R. R. Angew. Chem. 2009, 121, 1932-1967. Angew. Chem., Int. Ed. 2009, 48, 1900-1934.

(2) Toshima, K. Carbohydr. Res. 2006, 341, 1225-1240.

(3) Demchenko, A. V. Handbook of Chemical Glycosylation; WILEYVCH: Weinheim, 2008.

(4) Davis, B. G. J. Chem. Soc., Perkin Trans. 1 2000, 2137-2160.

(5) Pelissier, H. Tetrahedron 2005, 61, 2947-2993.

(6) Jung, K.-H.; Müller, M.; Schmidt, R. R. Chem. Rev. 2000, 100, $4423-4442$.

10.1021/ol201231v (C) 2011 American Chemical Society

Published on Web 06/15/2011 intramolecular glycosidation has attracted great interest. ${ }^{6}$ In this context it is emphasized that $O$-glycosyl trichloroacetimidates transfer the glycosyl moiety to phosphate esters and related $\mathrm{A}=\mathrm{B}-\mathrm{C}-\mathrm{H}$ systems without a catalyst highly diastereoselectively. ${ }^{1 \mathrm{a}, 7}$ Thus, from the $\alpha$-glucopyranosyl trichloroacetimidate (Scheme $1,1 \alpha$ ) via an eightmembered cyclic (extended cyclohexane-like) transition state the $\beta$-products and vice versa were obtained. Even $\alpha$-pyridone with a $\mathrm{p} K_{\mathrm{a}}$ of $\sim 12,{ }^{8}$ possessing the required $\mathrm{A}=\mathrm{B}-\mathrm{C}-\mathrm{H}$ geometry (Scheme 1 ), served as a substrate in this reaction. Hence, it is envisioned that corresponding $\mathrm{A}-\mathrm{B}-\mathrm{C}-\mathrm{H}$ type intermediates, reversibly generated from a catalyst $\mathrm{B}=\mathrm{C}$ (or $\mathrm{B} \equiv \mathrm{C}, \mathrm{B} \cdots \mathrm{C}$ ) and, for instance, alcohol as acceptor $\mathrm{A}-\mathrm{H}$, should react in the same way. ${ }^{7}$ Thus, the anomeric stereocontrol is connected via a concerted intramolecular acceptor transfer to the configuration of the glycosyl donor (Scheme 2).

The ideal catalyst $\mathrm{B}=\mathrm{C}$ should fulfill the following criteria: (a) very fast and reversible generation of the $\mathrm{A}-\mathrm{B}-\mathrm{C}-\mathrm{H}$ adduct with $\mathrm{A}-\mathrm{H}$; (b) increase of the proton acidity of $\mathrm{A}-\mathrm{H}$

(7) Schmidt, R. R.; Gaden, H.; Jatzke, H. Tetrahedron Lett. 1990, 31, 327-330.

(8) Perrin, D. D.; Dempsey, B.; Serjeant, E. P. In $p K_{a}$ Prediction for Organic Acids and Bases; Chapman and Hall: London, 1981; p 55. 
Scheme 1. Site-Selective Glycosidation of $\mathrm{A}=\mathrm{B}-\mathrm{C}-\mathrm{H}$ Acceptors with $O$-Glucopyranosyl Trichloroacetimidate As Donor Supporting an $\mathrm{S}_{\mathrm{N}} 2$-Type Mechanism

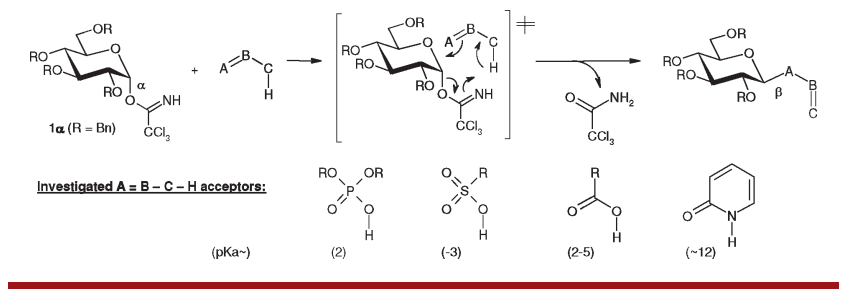

in the $\mathrm{A}-\mathrm{B}-\mathrm{C}-\mathrm{H}$ adduct; (c) no activation (this way eventually leading to decomposition) of the glycosyl donor in the absence of the acceptor $\mathrm{A}-\mathrm{H}$, thus supporting the intramolecular, bimolecular concerted reaction course of the A$\mathrm{B}-\mathrm{C}-\mathrm{H}$ adduct; (d) increase of the nucleophilicity of the acceptor hydroxy group to facilitate glycosidation.

Scheme 2. Formation of Intermediate Acceptor-Catalyst Adducts $\mathrm{A}-\mathrm{B}-\mathrm{C}-\mathrm{H}$ Reacting with $O$-Glucopyranosyl Trichloroacetimidate as Donor

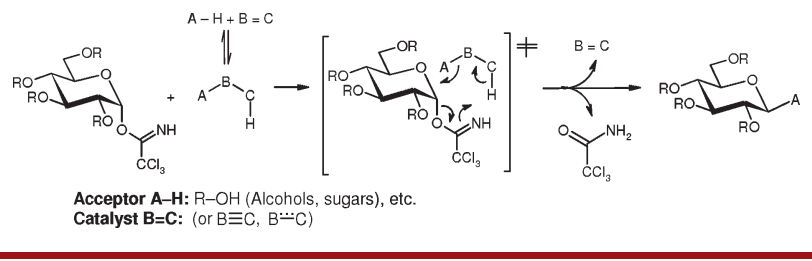

Studies along these lines with addition prone carbonyl compounds $^{7}$ and recently with electron-deficient imines ${ }^{9}$ as catalysts $\mathrm{B}=\mathrm{C}$ exhibited some success. However, the investigated compounds did not fully meet criteria (a), (c), and (d), thus leading also to undesired product formation.

Hence, $\mathrm{B}-\mathrm{F}$ bond containing compounds could be suitable for this purpose as the empty orbital at boron readily accepts oxygen containing compounds and the fluorine is known to form strong H-bonds. ${ }^{10}$ Thus with alcohols $\left(\mathrm{R}^{1}-\right.$ $\mathrm{OH}$ ) adducts are obtained that do not only provide an acidic proton that is $\mathrm{H}$-bonded to fluorine in nonpolar solvents ${ }^{10}$ but also an acceptor that carries an induced partial negative charge.

$$
R^{1} O^{\ominus}-{ }_{1}^{B}-F^{\oplus}-H^{-H}
$$

Thus, a nucleophilicity increase of the acceptor is gained that supports the reaction with the glycosyl donor. ${ }^{11,12}$ As

(9) Kumar, A.; Schmidt, R. R., unpublished results.

(10) (a) Huduall, T. W.; Melaimi, M.; Gabbai, F. P. Org. Lett. 2006, 8, 2747-2749. (b) He, Q.; Yang, J.; Meng, X.-m. Chin. J. Chem. Phys. $\mathbf{2 0 0 9}, 22,517-522$ and references therein.

(11) The activation of the acceptor in glycosidations has recently been addressed: (a) Ferrier, R. J.; Furneaux, R. H. Aust. J. Chem. 2009, 62, 585-589. (b) Kaji, E.; Nishino, T.; Ishige, K.; Ohyo, Y.; Shirai, Y. Tetrahedron Lett. 2010, 51, 1570-1573.

(12) By alkoxide groups negatively charged arylboronates were shown to be good acceptors in standard glycosidations: Oshima, K.; Aoyama, Y. J. Am. Chem. Soc. 1999, 121, 2315-2316. this intramolecular acid-base catalysis concept for glycosidations is related to the mechanism of glycosyl transfer in enzymatic reactions, ${ }^{6}$ proof of principle studies are of great interest. ${ }^{13}$

Boron trifluoride as a catalyst for $O$-glycosyl trichloroacetimidate activation favors, in low polarity solvents at low temperatures, $\mathrm{S}_{\mathrm{N}}$ 2-type reactions. Yet, the preferential inversion product formation is presumably due to tight ion pair generation prior to reaction with the glycosyl acceptor. ${ }^{1 \mathrm{a}, 14}$ Similar results were obtained with glycosyl iodides or with, under acid conditions, in situ generated $O$-glycosyl triflate intermediates, respectively, that also furnish preferentially inversion products formally based on $\mathrm{S}_{\mathrm{N}}$ 2-type reactions. ${ }^{15-17}$ However, these catalysts for leaving group activation do not fulfill criteria (c) as shown for boron trifluoride and TMSOTf (Table 1, entries 1 and 2 ); therefore the desired reaction course is not favored. Hence, for instance, less acidic boron fluoride derivatives are required as catalysts. As the first compound phenylboron difluoride $\left(\mathrm{PhBF}_{2}\right)$ was selected that could be prepared in pure form. ${ }^{18}$ Gratifyingly, this reagent fulfilled the criteria for a good catalyst system as shown in Table 1: At $0{ }^{\circ} \mathrm{C}$ (and even at $\mathrm{rt}$ ) $\mathrm{PhBF}_{2}$ did not activate and hence not

Table 1. Reaction of Glycosyl Donors $\mathbf{1} \boldsymbol{\alpha}-\mathbf{5} \alpha$ with Alcohols (A) under Various Conditions and Some Comparisons

\begin{tabular}{|c|c|c|c|c|c|c|}
\hline \multirow{2}{*}{\multicolumn{3}{|c|}{ entry donor acc. }} & \multirow[b]{2}{*}{$\begin{array}{l}\text { activator } \\
\text { (equiv) }\end{array}$} & \multicolumn{2}{|c|}{ reaction cond. $^{a}$} & \multirow[b]{2}{*}{$\begin{array}{cc}\text { product } & \beta / \alpha^{b} \\
\text { (yield) } & \text { ratio }\end{array}$} \\
\hline & & & & temp & time & \\
\hline 1 & $1 \alpha$ & \multirow{2}{*}{\multicolumn{2}{|c|}{ None $\mathrm{BF}_{3} \bullet \mathrm{OEt}_{2}(0.1)$}} & $0{ }^{\circ} \mathrm{C}$ & \multicolumn{2}{|c|}{$30 \min$ Decomp. of $1 \alpha$} \\
\hline 2 & $1 \alpha$ & & TMSOTf & $0{ }^{\circ} \mathrm{C}$ & $30 \mathrm{~min}$ & \multirow{2}{*}{$\begin{array}{l}\text { Decomp. of } 1 \alpha \\
\text { No reaction, } \\
\text { no decomp. }\end{array}$} \\
\hline 3 & $1 \alpha$ & Non & $\mathrm{PhBF}_{2}$ & $0^{\circ} \mathrm{C} \rightarrow \mathrm{r}$ & $2 \mathrm{~d}$ & \\
\hline 4 & & & 1) & 0 & \multicolumn{2}{|c|}{$10 \min \mathbf{1 A}(84 \%) 2: 1$} \\
\hline 5 & & & TM & $0{ }^{\circ} \mathrm{C}$ & \multicolumn{2}{|c|}{$10 \min \mathbf{1 A}(88 \%) 1: 1$} \\
\hline 6 & $1 \alpha$ & $\mathbf{A}$ & $\mathrm{PhBF}_{2}$ & $0{ }^{\circ} \mathrm{C}$ & \multicolumn{2}{|c|}{$10 \min \mathbf{1 A}(73 \%) 8: 1$} \\
\hline 7 & $1 \alpha$ & & & -7 & \multirow{3}{*}{\multicolumn{2}{|c|}{$\begin{array}{ll}10 \min \mathbf{1 A}(89 \%) & 6: 1 \\
10 \min \mathbf{1 A}(88 \%) & 12: 1 \\
10 \min \mathbf{1 A}(93 \%) & 24: 1\end{array}$}} \\
\hline 8 & $1 \alpha$ & & {$[1 \mathrm{I}$} & -7 & & \\
\hline 9 & $1 \alpha$ & $\mathbf{A}$ & $\mathrm{PhBF}_{2}(0.1)$ & -7 & & \\
\hline 10 & $1 \alpha$ & $\mathbf{A}^{\prime d}$ & 115 & $0^{\circ} \mathrm{C}$ & \multicolumn{2}{|c|}{$10 \min \mathbf{1 A}(71 \%) 24: 1$} \\
\hline 11 & $3 \alpha$ & & $\mathrm{hB}$ & -7 & \multirow{4}{*}{\multicolumn{2}{|c|}{ 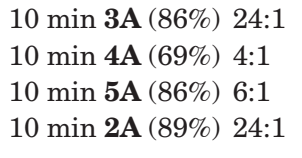 }} \\
\hline 12 & $4 \alpha$ & $\mathbf{A}$ & $\mathrm{PhBF}_{2}(0.1)$ & $-78^{\circ} \mathrm{C}$ & & \\
\hline 13 & $5 \alpha$ & $\mathbf{A}$ & $\mathrm{PhBF}_{2}(0$ & $-78^{\circ} \mathrm{C}$ & & \\
\hline 14 & $2 \alpha$ & $\mathbf{A}$ & $\mathrm{PhBF}_{2}(0.1)$ & $-78^{\circ} \mathrm{C}$ & & \\
\hline 15 & $1 \alpha$ & None & $\mathrm{Ph}_{2} \mathrm{~B}$ & $0^{\circ} \mathrm{C}$ & \multirow{3}{*}{\multicolumn{2}{|c|}{ 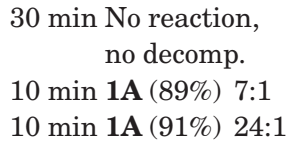 }} \\
\hline 16 & $1 \alpha$ & $\mathbf{A}$ & $x_{2}$ & $0^{\circ}$ & & \\
\hline 17 & $1 \alpha$ & $\mathbf{A}$ & $\mathrm{Ph}_{2} \mathrm{~B}$ & -78 & & \\
\hline 18 & $1 \beta$ & & & -7 & & $1: 4$ \\
\hline 19 & $1 \beta$ & B & $\mathrm{PhBF}_{2}($ & $-78^{\circ} \mathrm{C}$ & $10 \mathrm{~min}$ & 1B $(90 \%) \quad 1: 15$ \\
\hline
\end{tabular}

${ }^{a}$ Inverse procedure and dry $\mathrm{CH}_{2} \mathrm{Cl}_{2}$ as solvent were employed. ${ }^{b}$ The $\beta / \alpha$ ratio was determined by the ${ }^{1} \mathrm{H}$ NMR signals of the isopropyl methyl groups; the detection limit for the $\alpha$-anomer is about $4 \%$. ${ }^{c}$ Very slow formation of glucosyl fluoride was observed. ${ }^{d} \mathbf{A}^{\prime}=\mathrm{B}\left(\mathrm{O}^{\mathrm{i}} \mathrm{Pr}\right)_{3}$. 
Scheme 3. Glycosyl Donors $\mathbf{1} \boldsymbol{\alpha}-\mathbf{5} \boldsymbol{\alpha}$ and Their Reactions with Alcohols (for details, see Table 1)

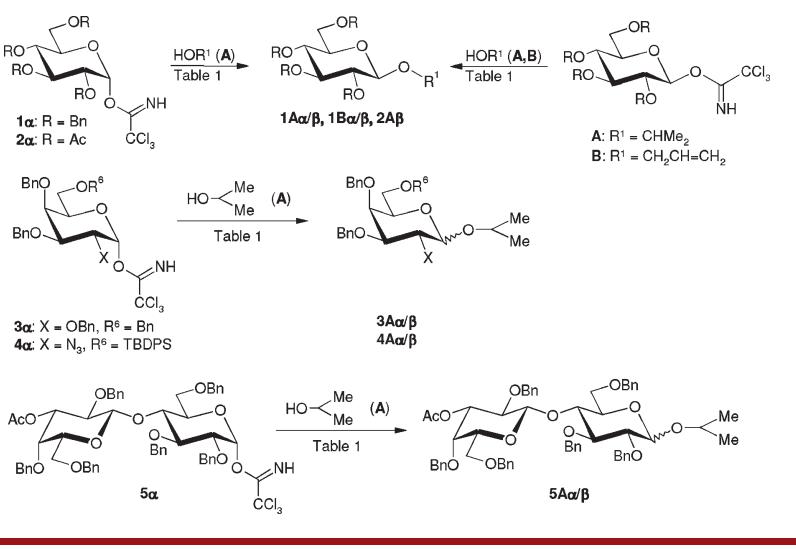

decompose the donor $1 \alpha$ (entry 3 ); however, fast adduct formation with isopropanol could be observed by ${ }^{1} \mathrm{H}$ NMR studies. This adduct reacted readily with $1 \alpha^{19}$ at $0{ }^{\circ} \mathrm{C}$ or even at $-78{ }^{\circ} \mathrm{C}$ to afford essentially (entry 6) or practically exclusively (entry 9 ) the desired $\beta$-glucopyranoside 1A. ${ }^{20}$ Comparisons with $\mathrm{BF}_{2} \cdot \mathrm{OEt}_{2}$ and TMSOTf as a catalyst under these conditions (entries 4, 5 and 7,8 ) clearly showed that the $\mathrm{PhBF}_{2} \cdot$ alcohol adduct is superior in terms of stereocontrol. Comparison studies with alkyl phenylboronates and borate esters as acceptors and HF as a promoter (entry 10) led to similar results. These studies showed that fluorine bound to boron is required for the success of the reaction. As presumed, the transition state in the reaction of $1 \alpha$ with the $\mathrm{A}-\mathrm{B}-\mathrm{C}-\mathrm{H}$ adduct is quite sensitive to temperature variations (entries 6 and 9); however, solvents (as for instance acetonitrile, toluene, cyclohexane) had only a minor effect on the results. Due to the fast adduct formation, the use of the inverse procedure (IP, i.e. adding the catalyst to the dissolved acceptor) or the normal procedure (NP, i.e. adding the catalyst to a solution of the acceptor and donor) had only a small effect on the result (not shown). Hence, $\mathrm{PhBF}_{2}$ as the catalyst in dichloromethane as the solvent at $-78^{\circ} \mathrm{C}$ under IP conditions seems to be a good choice for the synthesis of 1,2trans glycosides with $1 \alpha$ as the donor. Similar results were

(13) The activation of $O$-glycosyl trichloroacetimidates with $\mathrm{HBF}_{4}$ follows the standard reaction course: (a) Chiba, H.; Funasake, S.; Mukaiyama, T. Bull. Soc. Chem. Jpn. 2003, 76, 1629-1644.'(b) Hashihayata,

T.; Mandai, H.; Mukaiyama, T. Chem. Lett. 2003, 32, 442-443.

(14) Weingart, R.; Schmidt, R. R. Tetrahedron Lett. 2000, 41, 87538758 .

(15) (a) El-Badry, M. H.; Gervay-Hague, J. Tetrahedron Lett. 2005, 46, 6727-6728. (b) El-Badry, M. H.; Willenbring, D.; Tantillo, D. J.; Gervay-Hague, J. J. Org. Chem. 2007, 72, 4663-4672.

(16) Crich, D. Acc. Chem. Res. 2010, 43, 1144-1153 and references therein.

(17) Callam, C. S.; Gadikota, R. R.; Klein, D. M.; Lowary, T. L. J. Am. Chem. Soc. 2003, 125, 13112-13119.

(18) Farvoq, O. J. Fluorine Chem. 1995, 70, 225-227.

(19) Schmidt, R. R.; Michel, J. Angew. Chem. 1980, 92, 763-764. Angew. Chem., Int. Ed. Engl. 1980, 19, 731-732.

(20) Briner, K.; Vasella, A. Helv. Chim. Acta 1989, 72, 1371-1382. 375.
Table 2. Reaction of Glycosyl Donors $\mathbf{1} \alpha-5 \alpha$ with Carbohydrate Acceptors $\mathbf{B}-\mathbf{G}$ with $\mathrm{PhBF}_{2}$ or $\mathrm{Ph}_{2} \mathrm{BF}$, Respectively, As Catalysts
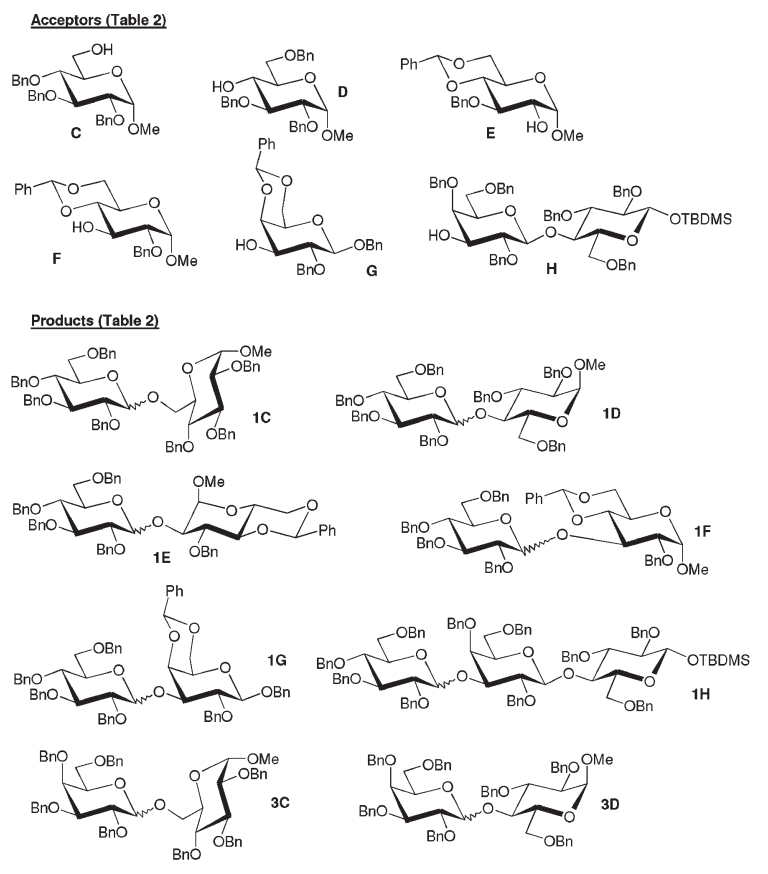

$\underbrace{\mathrm{B}}_{\mathrm{N}_{3}}$
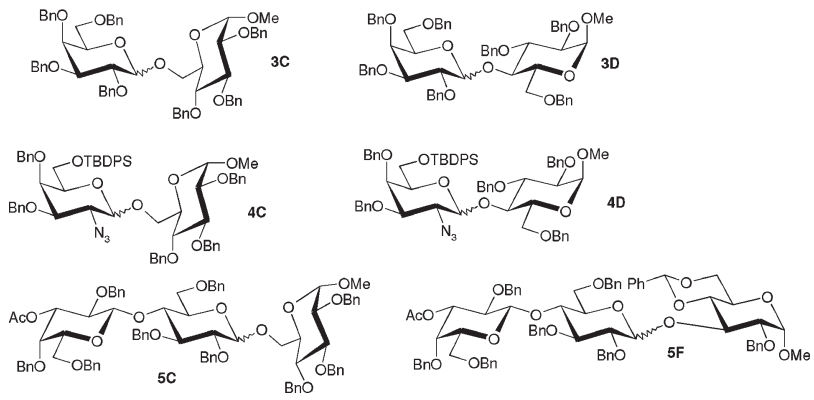

\begin{tabular}{|c|c|c|c|c|c|c|c|}
\hline \multirow[b]{2}{*}{ entry } & \multirow[b]{2}{*}{ donor } & \multirow[b]{2}{*}{ acc. } & \multirow{2}{*}{$\begin{array}{l}\text { catalyst } \\
\text { (equiv) }\end{array}$} & \multicolumn{2}{|c|}{ reaction cond. ${ }^{a}$} & \multirow{2}{*}{$\begin{array}{l}\text { product } \\
\text { (yield) }\end{array}$} & \multirow{2}{*}{$\begin{array}{l}\beta / \alpha^{b} \\
\text { ratio }\end{array}$} \\
\hline & & & & temp & time & & \\
\hline 1 & $1 \alpha$ & $\mathbf{C}$ & $\mathrm{PhBF}_{2}(0.1)$ & $0^{\circ} \mathrm{C}$ & $10 \mathrm{~min}$ & $\mathbf{1 C}(83 \%)$ & $13: 1$ \\
\hline 2 & $1 \alpha$ & $\mathbf{C}$ & $\mathrm{PhBF}_{2}(0.1)$ & $-78^{\circ} \mathrm{C}$ & $10 \mathrm{~min}$ & $\mathbf{1 C}(87 \%)$ & $24: 1$ \\
\hline 3 & $1 \alpha$ & $\mathbf{C}$ & TMSOTf (0.1) & $-78^{\circ} \mathrm{C}$ & $10 \mathrm{~min}$ & $\mathbf{1 C}(80 \%)$ & $6: 1$ \\
\hline 4 & $1 \alpha$ & D & $\mathrm{PhBF}_{2}(0.1)$ & $-78^{\circ} \mathrm{C}$ & $10 \mathrm{~min}$ & $1 \mathbf{D}(73 \%)^{c}$ & $4: 1$ \\
\hline 5 & $1 \alpha$ & $\mathbf{E}$ & $\mathrm{PhBF}_{2}(0.1)$ & $-78^{\circ} \mathrm{C}$ & $10 \mathrm{~min}$ & $\mathbf{1 E}(74 \%)^{c}$ & $8: 1$ \\
\hline 6 & $1 \alpha$ & $\mathbf{F}$ & $\mathrm{PhBF}_{2}(0.1)$ & $-78^{\circ} \mathrm{C}$ & $10 \mathrm{~min}$ & $\mathbf{1 F}(65 \%)$ & $3: 1$ \\
\hline 7 & $1 \alpha$ & $\mathbf{G}$ & $\mathrm{PhBF}_{2}(0.1)$ & $-78^{\circ} \mathrm{C}$ & $10 \mathrm{~min}$ & $\mathbf{1 G}(62 \%)^{c}$ & $15: 1$ \\
\hline 8 & $1 \alpha$ & $\mathbf{H}$ & $\mathrm{PhBF}_{2}(0.1)$ & $-78^{\circ} \mathrm{C}$ & $4 \mathrm{~h}$ & $\mathbf{1 H}(64 \%)$ & $24: 1$ \\
\hline 9 & $1 \alpha$ & $\mathbf{H}$ & $\mathrm{BF}_{3} \bullet \mathrm{OEt}_{2}(0.1)$ & $-78^{\circ} \mathrm{C}$ & $3 \mathrm{~h}$ & $\mathbf{1 H}(66 \%)$ & $5: 1$ \\
\hline 10 & $3 \alpha$ & $\mathbf{C}$ & $\mathrm{PhBF}_{2}(0.1)$ & $-78^{\circ} \mathrm{C}$ & $10 \mathrm{~min}$ & $\mathbf{3 C}(82 \%)$ & $24: 1$ \\
\hline 11 & $3 \alpha$ & D & $\mathrm{PhBF}_{2}(0.1)$ & $-78^{\circ} \mathrm{C}$ & $10 \mathrm{~min}$ & 3D $(68 \%)$ & $3: 1$ \\
\hline 12 & $4 \alpha$ & $\mathbf{C}$ & $\mathrm{PhBF}_{2}(0.1)$ & $-78^{\circ} \mathrm{C}$ & $10 \mathrm{~min}$ & $4 \mathrm{C}(68 \%)$ & $24: 1$ \\
\hline 13 & $4 \alpha$ & $\mathbf{D}$ & $\mathrm{PhBF}_{2}(0.1)$ & $-78^{\circ} \mathrm{C}$ & $30 \mathrm{~min}$ & 4D $(68 \%)$ & $4: 1$ \\
\hline 14 & $5 \alpha$ & $\mathbf{C}$ & $\mathrm{PhBF}_{2}(0.1)$ & $-78^{\circ} \mathrm{C}$ & $10 \mathrm{~min}$ & $\mathbf{5 C}(72 \%)$ & $24: 1$ \\
\hline 15 & $5 \alpha$ & $\mathbf{F}$ & $\mathrm{PhBF}_{2}(0.1)$ & $-78^{\circ} \mathrm{C}$ & $10 \mathrm{~min}$ & $\mathbf{5 F}(60 \%)$ & $7: 1$ \\
\hline 16 & $1 \alpha$ & $\mathbf{C}$ & $\mathrm{Ph}_{2} \mathrm{BF}(0.1)$ & $-78^{\circ} \mathrm{C}$ & $10 \mathrm{r}$ & $1 \mathrm{C}(96 \%)$ & $24: 1$ \\
\hline 17 & $1 \alpha$ & D & $\mathrm{Ph}_{2} \mathrm{BF}(0.1)$ & $-78^{\circ} \mathrm{C}$ & $10 \mathrm{~min}$ & $1 D(74 \%)$ & $10: 1$ \\
\hline 18 & $3 \alpha$ & D & $\mathrm{Ph}_{2} \mathrm{BF}(0.1)$ & $-78^{\circ} \mathrm{C}$ & $10 \mathrm{~min}$ & $\mathbf{3 D}(76 \%)$ & $6: 1$ \\
\hline 19 & $4 \alpha$ & $\mathbf{C}$ & $\mathrm{Ph}_{2} \mathrm{BF}(0.1)$ & $-78^{\circ} \mathrm{C}$ & $10 \mathrm{~min}$ & $\mathbf{4 C}(71 \%)$ & $24: 1$ \\
\hline 20 & $5 \alpha$ & $\mathbf{C}$ & $\mathrm{Ph}_{2} \mathrm{BF}(0.1)$ & $-78^{\circ} \mathrm{C}$ & $10 \mathrm{~min}$ & $\mathbf{5 C}(80 \%)$ & $24: 1$ \\
\hline
\end{tabular}

${ }^{a}$ All reactions were carried out in dry $\mathrm{CH}_{2} \mathrm{Cl}_{2}$ as solvent using the inverse procedure. ${ }^{b}$ The $\beta / \alpha$ ratio was determined with the help of ${ }^{1} \mathrm{H}$ NMR data; the detection limit for the $\alpha$-anomers is about $4 \%$. ${ }^{c}$ About $5 \%$ glucosyl fluoride was obtained. 
obtained for glycosyl donors $3 \alpha,^{21} \mathbf{4} \alpha,{ }^{22}$ and $\mathbf{5} \alpha^{23}$ having no anchimerically assisting neighboring groups in the 2-position; again, mainly the $\beta$-glycosides of $\mathbf{3 A},{ }^{24} \mathbf{4 A}$, and $\mathbf{5 A}$ were formed (entries 11, 12, and 13). Even the less reactive fully $O$-acetylated glucosyl donor $2 \alpha^{19}$ could be activated with $\mathrm{PhBF}_{2}$ in the presence of isopropanol as an acceptor (entry 14 ) furnishing as expected the $\beta$-glucopyranoside $\mathbf{2 A} \boldsymbol{\beta}$ (Scheme 3 ). ${ }^{25}$

As $\mathrm{PhBF}_{2}$ gave mainly excellent glycosidation results at temperatures as low as $-78{ }^{\circ} \mathrm{C}$, hence also the less Lewis acidic $\mathrm{Ph}_{2} \mathrm{BF}$ was prepared ${ }^{18}$ and studied as a catalyst under the same conditions. Entries 15-17 (Table 1) show that this compound also fulfills the criteria for a good catalyst.

Preliminary experiments were also performed with the corresponding $O-\beta$-D-glucopyranosyl trichloroacetimidate $\mathbf{1} \boldsymbol{\beta}^{1 \mathrm{a}}$ as a glycosyl donor. With isopropanol (A) as the acceptor there is a clear preference for $\alpha$-product $(\mathbf{1} \mathbf{A} \boldsymbol{\alpha})^{26}$ formation (entry 18). Almost exclusive $\beta$-selectivity was observed for allyl alcohol (B) as the acceptor affording mainly $\mathbf{1 B} \boldsymbol{\alpha}^{27}$ (entry 19). Possibly, some steric hindrance in the transition state leads to lower anomeric selectivity than observed for $1 \alpha$. Hence, other catalyst types may be required for the selective generation of 1,2-cis-glycosides.

The glycosidation results with glycosyl donors $1 \alpha, 3 \alpha$, $4 \alpha$, and $5 \alpha$ with more demanding carbohydrate acceptors $\mathbf{C},{ }^{26} \mathbf{D},{ }^{29} \mathbf{E},{ }^{30} \mathbf{F},{ }^{30} \mathbf{G},{ }^{31}$ and $\mathbf{H}^{32}$ in the presence of different catalysts are compiled in Table 2 . Reaction of $1 \alpha$ with these acceptors having unprotected hydroxy groups at 6-, 4-, 2-, and 3-positions with $\mathrm{PhBF}_{2}$ as the catalyst (entries 1, 2, $4-8$ ) exhibited preferential formation of the $\beta$-glucopyranosides of $\mathbf{1 C},{ }^{28} \mathbf{1 D},{ }^{21} \mathbf{1 E},{ }^{33} \mathbf{1 F},{ }^{34} \mathbf{1 G},{ }^{35}$ and $\mathbf{1 H}$. The reactions did not proceed at the same rate (entry 8); the appearance of some glycosyl fluoride (entries $4,5,7$ ) showed that the catalyst is partly consumed, thus leading to a decreased reaction rate that also influenced the product yield. However, no phenyl C-glycoside formation was observed. ${ }^{36}$ TMSOTf or $\mathrm{BF}_{3} \cdot \mathrm{OEt}_{2}$ as catalysts did not

(22) Dere, R. T.; Kumar, A.; Kumar, V.; Zhu, X.; Schmidt, R. R. J. Org. Chem., submitted.

(23) Knerr, L.; Schmidt, R. R. Synlett 1999, 1802-1804.

(24) Mereyala, H. B.; Reddy, G. V. Tetrahedron 1991, 47, 6435-6438. 208.

(25) Lemieux, R. U.; Hindsgaul, O. Carbohydr. Res. 1980, 82, 195-

(26) Tsvetkov, Y. E.; Klotz, W.; Schmidt, R. R. Liebigs Ann. Chem. 1992, 371-375.

(27) Ronchi, P.; Vignando, S.; Guglieri, S.; Polito, L.; Lay, L. Org. Biomol. Chem. 2009, 7, 2635-2644.

(28) Eby, R.; Schuerch, C. Carboyhdr. Res. 1974, 34, 79-90.

(29) Garegg, P. J.; Iversen, T.; Oscarson, S. Carbohydr. Res. 1976, 50, 12-11-14.

(30) Barrett, A. G. M.; Road, R. W.; Barton, D. H. R. J. Chem. Soc., Perkin Trans. 1 1980, 2184-2190.

(31) Westerlind, U.; Hagback, R.; Duk, M.; Norberg, T. Carbohydr. Res. 2002, 337, 1517-1522.

(32) Roussel, F.; Knerr, L.; Schmidt, R. R. Eur. J. Org. Chem. 2001, 2067-2073.

(33) Nagai, H.; Sasaki, K.; Matsumura, S.; Toshima, K. Carbohydr. Res. 2005, 340, 337-353. furnish better results than $\mathrm{PhBF}_{2}$, for instance in the formation of $\mathbf{1 C}$ or $\mathbf{1 H}$ (entries 3 and 9). Preferential 1,2trans product formation was also observed for glycosyl donors $\mathbf{3} \boldsymbol{\alpha}-\mathbf{5} \boldsymbol{\alpha}$ (entries $10-15$ ), thus furnishing mainly $3 \mathrm{C} \beta,{ }^{37} 3 \mathrm{D} \beta,{ }^{21} 4 \mathrm{C} \beta, 4 \mathrm{D} \beta, 5 \mathrm{C} \beta$, and $5 \mathrm{~F} \beta$.

Investigations with $\mathrm{Ph}_{2} \mathrm{BF}$ as the catalyst (entries 16-20, formation of $\mathbf{1 C}, \mathbf{1 D}, \mathbf{3 D}, \mathbf{4 C}, \mathbf{5 C}$ ) exhibited very good glycosidation results. It was particularly pleasing that $\mathrm{Ph}_{2} \mathrm{BF}$ provided in the reactions of $1 \alpha$ with $\mathrm{D}$ to $\mathbf{1 D}$ (entry 17) and of $\mathbf{3} \alpha$ with $\mathbf{D}$ to $\mathbf{3 D}$ (entry 18 ) better results than $\mathrm{PhBF}_{2}$ (see entries 4 and 11); thus, as expected, the steric effect of the two phenyl groups supports the concerted donor activation-acceptor transfer. Hence, the choice of catalyst is of great importance in these intramolecular acid-base catalyzed glycosidations.

In conclusion, $\mathrm{PhBF}_{2}$ and $\mathrm{Ph}_{2} \mathrm{BF}$, formally representing $\mathrm{B}=\mathrm{C}$, basically fulfill the requirements for good catalysts for $O$-glycosyl trichloroacetimidate (and related systems) activation: Not the catalyst itself, but only the adduct $\mathrm{A}-\mathrm{B}-\mathrm{C}-\mathrm{H}$ with acceptor $\mathrm{A}-\mathrm{H}$ is sufficiently acidic to activate the glycosyl donor. Hence, the catalyst carries the acceptor to the donor generating a temporarily H-bonded noncovalent donor leaving groupcatalyst-acceptor complex that permits via an intramolecular reaction course proton transfer to the leaving group and the nucleophilicity increase of the acceptor facilitating the concomitant glycoside bond formation. The results support the prevalence of this concerted $\mathrm{S}_{\mathrm{N}}$ 2-type mechanism between the glycosyl donor and the $\mathrm{A}-\mathrm{B}-\mathrm{C}-\mathrm{H}$ adduct, as preferentially the inversion product is obtained. Competing reaction courses leading to $\alpha$-product and glycosyl fluoride formation were only effective in some cases. H-bonding as a means for intramolecular acid-base catalyzed glycosidation resulting in concomitant glycosyl donor and glycosyl acceptor activation obviously has the potential to become a general and very efficient glycosidation method.

Acknowledgment. This work was supported by the University of Konstanz and the Fonds der Chemischen Industrie. V.K. is particularly grateful for a fellowship from the Alexander von Humboldt Foundation.

Supporting Information Available. Experimental details and NMR spectra of new compounds $(\mathbf{1 H}, \mathbf{4 A}, \mathbf{4 C}, \mathbf{4 D}$, 5A, 5C, 5F) and NMR spectra of 1A-1G, 2A, 3A, 3C, 3D. This material is available free of charge via the Internet at http://pubs.acs.org.

(34) Ito, Y.; Ogawa, T. Carbohydr. Res. 1990, 202, 165-175.

(35) Cassel, S.; Plessis, I.; Wessel, H. P.; Rollin, P. Tetrahedron Lett. 1998, 39, 8097-8100.

(36) Mitchell, T. A.; Bode, J. W. J. Am. Chem. Soc. 2009, 131, 1805718059 and references therein.

(37) Vankar, Y. D.; Vankar, P. S.; Behrendt, M. E.; Schmidt, R. R. Tetrahedron 1991, 47, 9985-9992. 